\title{
Hypersensitivity pneumonitis: clinical, radiological and pathological profile of 103 patients from North India
}

\author{
Raj Kumar, Sonam Spalgais, Vikrant Ranga \\ Department of Pulmonary Medicine, Vallabhbhai Patel Chest Institute, University of Delhi, India
}

\begin{abstract}
Hypersensitivity pneumonitis (HP) is an interstitial lung disease, commonly occurring due to exposure to various inciting agent related to occupation. Few studies have shown that it can also occur without any occupation exposure. In this study we are presenting clinical, radiological and bronchoscopic finding of 103 HP patients. We retrospective analysis of $5 \frac{1}{2}$ years HP patient's data from a chest institute of India. The diagnosis of HP was considered with following criteria: i) known exposure to an inciting
\end{abstract}

Correspondence: Raj Kumar, Department of Pulmonary Medicine, Vallabhbhai Patel Chest Institute, University of Delhi, New Delhi 110007, India.

Mobile: +91.9810146835 - Tel. +91.1127402409.

E-mail: rajkumarvpci@gmail.com

Key words: Hypersensitivity pneumonitis; occupational; bronchoscopy; environmental.

Contributions: RK, study concept and design, manuscript drafting and reviewing for intellectual content; SS, study concept and design, manuscript drafting, data acquisition and interpretation; VR, data acquisition, analysis and interpretation, manuscript drafting. All the authors have read and approved the final version of the manuscript and agreed to be accountable for all aspects of the work.

Conflict of interest: The authors declare no conflict of interest.

Funding: None.

Availability of data and materials: All data generated or analyzed during this study are included in this published article.

Patient consent for publication: Not applicable.

Conference presentation: NAPCON 2019.

Received for publication: 14 April 2020.

Accepted for publication: 5 June 2020.

${ }^{\circ}$ Copyright: the Author(s), 2020

Licensee PAGEPress, Italy

Monaldi Archives for Chest Disease 2020; 90:1307

doi: 10.4081/monaldi.2020.1307

This article is distributed under the terms of the Creative Commons Attribution Noncommercial License (by-nc 4.0) which permits any noncommercial use, distribution, and reproduction in any medium, provided the original author(s) and source are credited. antigen; ii) presence of respiratory symptoms; iii) radiologic evidence of diffuse lung disease; iv) no other identifiable cause; v) lung biopsy specimen that demonstrated features of HP; and vi) bronchoalveolar lavage lymphocytosis $(\geq 30 \%)$. The mean \pm SD age was $47 \pm 12.8$ years; $67 \%$ were female. The common symptoms were cough (97\%) and dyspnea (91\%). History of exposure to inciting agent was present in $61 \%$ with pigeon exposure being the most common (56\%). Majority of patients (86\%) were having chronic symptoms for $>6$ months. On $6 \mathrm{MWT}$ oxygen desaturation $>4 \%$ was seen in $57 \%$ patients. Centrilobular nodules $(61 \%)$ and ground glass opacity $(47.5 \%)$ were common finding on HRCT chest. Bronchoalveolar lavage (BAL) lymphocytosis $>30 \%$ was present in $48.5 \%$ and histopathological diagnosis HP on transbronchial lung biopsy (TBLB) and/or endobronchial lung biopsy (EBLB) was in 50\% patients. HP is exposure related environmental disease, as it can occur without any occupational history. Bronchoscopy with BAL and lung biopsy should do in all suspected cases to confirm diagnosis in our country as it is less invasive, day care procedure with less complication.

\section{Introduction}

Hypersensitivity pneumonitis (HP) is an immune mediated lung disease resulting from the inhalation of an antigen. It was first described as an occupational disease by Ramazzini [1]. Since then, a lot of causative factor have been identified and the pathogenesis is now better understood [2]. Currently $>200$ antigens are known to be involved. They are mostly proteins or glycoproteins derived from fungal, bacterial, or animal proteins but can also be small molecular weight chemicals [2,3].

The incidence and prevalence varies considerably around the world due to lack of internationally accepted uniform diagnostic criteria, as well as the different seasonal, geographical condition and host factors [4,5]. The incidence of HP range $0.3-0.9$ per 100,000 individuals in western countries [6-9]. In 3 European countries, HP accounts for $4-15 \%$ of all interstitial lung disease (ILD) [10]. The studies on high-risk occupations reported, that the HP account for $19 \%$ in farmers exposed to moldy hay and $6-20 \%$ in bird fancier's lung by exposure to bird droppings $[11,12]$. In India different studies showed that it accounts for 2.4 to $10.7 \%$ of all ILD patients [1315]. The Indian ILD registry, reported that HP was the most common new-onset ILD accounting for $47 \%$ cases [16].

The clinical manifestations depends on the antigen type, intensity and duration of exposure, susceptibility and resulting immune responses and it is categorized into acute, subacute and chronic [17]. Vasakova et al., recently, classified into acute/inflammatory and chronic/fibrotic HP based on clinical, radiological and pathological correlation with better prognostic value [3]. 
The diagnosis required multidisciplinary approach with minimum of pulmonologist, radiologist and pathologist. The common differential diagnoses are idiopathic pulmonary fibrosis (IPF), sarcodiosis, non-specific interstitial pneumonia (NSIP), smoking related lung disease, infection and pulmonary edema $[18,19]$. The diagnostic tests are required to minimised the differential diagnosis. The important diagnostic tests for HP are high-resolution computed tomography (HRCT) chest, serum precipitin and bronchoscopy. The laboratory test for confirmation of the suspect antigen is done by specific IgG. The IgG positivity means only sensitization/exposure to the antigen, not diagnostic $[3,20]$. As per Johannson et al. diagnostic predictive model of chronic HP, the combination of patient history of bird exposure, HRCT groundglass opacity (GGO), and mosaic perfusion with age has a specificity of $91 \%$ and a sensitivity of $48 \%$ [21]. Traditionally HP is considered as an occupational disorder that associated with massive exposure to an antigen in an agricultural setting (farmer's lung disease), hobbyist (e.g. bird fancier disease) and industrial setting. However recent studies suggest that antigen and its exposure in the environment may also play an increasing role in pathogenesis of HP [22-24]. In this study, we undertook the data analysis of 103 patients to evaluate the role of clinical profile, pulmonary function test, HRCT chest and bronchoalveolar lavage (BAL)/ bronchoscopic biopsy for diagnosis of HP in north Indian population.

\section{Methods}

This study was a retrospective analysis of 103 adult HP patients, registered between October 2013 and March 2019 at one of the unit of Pulmonary Medicine Department of Vallabhbhai Patel Chest Institute, a tertiary care chest institute in Delhi, India. At the time of registration, HP suspected patients underwent a symptom screening with special exposure history, general and respiratory physical examination, chest X-ray, routine blood tests, sputum examination, connective tissue serology, 6-min work test (6MWT), complete pulmonary function test (PFT) with diffusing capacity of carbon monoxide (DLCO), high resolution computer tomography (HRCT) chest, fibrooptic bronchoscopy with BAL, transbronchial lung biopsy (TBLB) and endobronchial lung biopsy (EBLB) in selected patients. The file of all registers patients with investigations, clinical details and other relevant data with diagnosis on file's cover has been kept in record in our hospital as an institute protocol. The patient's files with diagnosis of hypersensitivity pneumonitis were included for this study. All included files were scrutinized for diagnosis of HP, including clinical details, HRCT chest, PFT, baseline $\mathrm{SPO}_{2}, 6 \mathrm{MWT}$ and BAL fluid and histopathological finding. Data was extracted and entered in standard research forms.

\section{Diagnosis of hypersensitivity pneumonia}

As per the departmental protocol HP diagnosis was done on the basis of multidisciplinary approach. Diagnosis of HP was considered when the following criteria were present: i) known exposure to an inciting antigen; ii) presence of respiratory symptoms suggestive of ILD; iii) HRCT evidence of HP; iv) rule out all other known causes of ILDs; v) TBLB that demonstrated features of HP; vi) BAL lymphocytosis $(\geq 30 \%)$.

\section{Exposure history}

The history of exposure was considered necessary for diagnosis of HP, when there is a history of exposure to inciting agent for a minimum of 3-6 months at patient's residence or working place. The history of exposure was considered and taken particularly for pigeons, hay, molds, cotton dust and animal dander. Pigeon exposure means presence of pigeons at patient's resident or working place with evidences of droppings or feathers at windows, roof, veranda, etc.

\section{Chest HRCT}

The HRCT findings for HP diagnosis are: ground-glass opacities, centrilobular nodules and mosaic attenuation predominantly of upper and middle lobes in acute stage and fibrosis i.e reticulation, architectural distortion and traction bronchiectasis with or without honeycomb change of any zonal distribution particularly peribronchovascular distribution in chronic stage [3,25-29].

\section{Bronchoalveolar lavage}

BAL fluid lymphocytosis is one of the diagnostic finding of HP. BAL lymphocytosis of ( $>30 \%$ non-smoker and $>20 \%$ smokers) is considered as the "gold standard" criteria for HP prediction rule. BAL lymphocytosis with HRCT changes is considered as one of the standard criteria of HP diagnosis [25].

\section{Lung biopsy}

The histopathological diagnosis was considered with the following characteristic of TBLB: bronchiolocentriclymphohistiocytic interstitial pneumonia with chronic bronchiolitis and poorly formed, nonnecrotising granulomas in acute phase and airwaycentered fibrosis with few normal airways with or without inflammatory cells in fibrotic phase [3,25,30-33].

\section{Pulmonary function test}

PFT was interpreted as obstructive defect when forced expiratory volume in 1 second $\left(\mathrm{FEV}_{1}\right)$ to forced vital capacity (FVC) ratio is $<0.70$ with total lung capacity (TLC) $>80 \%$ predicted and the severity was graded by the percentage of predicted $\left(\mathrm{FEV}_{1}\right.$ (mild, $\geq 80 \%$; moderate, $79 \%-50 \%$; and severe, $<49-30 \%$; very severe $<30 \%)$. Restrictive defect when $\left(\mathrm{FEV}_{1} / \mathrm{FVC}>0.70\right.$ and TLC $<80 \%$ predicted; the severity of restriction was quantified by the percentage of predicted TLC (mild $80-70 \%$; moderate $69-60 \%$; severe $<60 \%$ ). Mixed pattern abnormality defined as coexistence of a restrictive defect and an obstructive defect. Decrease DLCO was considered when it was $<80 \%$ of predicted $[34,35]$.

\section{Data analysis}

The data accrued on all the patients diagnosed as HP was compiled and analysed using Microsoft Office Excel software. Continuous data is presented as mean with standard deviation or median and inter-quartile range (due to extreme values) and categorical data is presented as percentages. The institutional review board was informed for this study.

\section{Results}

The study included 103 diagnosed cases of HP on the basis of multidisciplinary approach. The mean \pm SD age was $47 \pm 12.8$ years. The majority of patients, 69 (67\%), were female, and $34(33 \%)$ were male. The history of exposure to inciting agent was present in $63(61 \%)$. Pigeon exposure was the most common exposure, seen in $58(56 \%)$ patients, two each cases with exposure to dog dander and molds, while only one with cotton dust exposure (Table 1). 
The common presenting symptoms were cough (97\%) and dyspnea (91\%). The other symptoms were fever and weight loss. Most of the patients $89(86.4 \%)$ were having symptoms for $>6$ months and remaining 14 (13.5\%) patients for $<6$ months. The digital clubbing was present in $16(15.5 \%)$ patients. The mean oxygen saturation was $96 \%$ on room air. The auscultatory respiratory finding were crackle in $70(68 \%)$ and rhonchi $3(3 \%)$ patients (Table 1$)$.

The PFT procedure was not able to perform after repeated try in two cases. Out of 101 PFT report spirometry was abnormal in 78 patients $(78 \%)$, with restrictive defect in $69(88 \%)$, obstructive defect in $4(5 \%)$ and mixed pattern in $5(6 \%)$. The diffusion capacity of lung was decrease in $66(84.6 \%)$ of abnormal spirometry patients. Both spirometry and DLCO were normal in $16(16 \%)$ (Table 2). The 6MWT was done in $91(88.3 \%$ ) and remaining $12(12 \%)$ patients was not able to perform. The details are summarized in Table 1.

The chest HRCT was done in all patients. The common finding of HP are centrilobular nodules (CLN) in 63(61\%), ground glass opacity (GGO) in $57(55.3 \%)$, septal thickening in $33(32 \%)$, mosaic attenuation in $15(14.5 \%)$, while the less common findings are honey combing $06(5.8 \%)$ and traction bronchiectesis 05 (4.8\%). The common combinations of HRCT finding, suggestive of HP are shown in Table 3 (see also Figures 1-3).

We are performing bronchoscopy in every patient of suspected ILD as per our departmental protocol to diagnosis or rule out the type of ILD. All the patients of this study were undergone bronchoscopic procedure with BAL with TBLB and/or EBLB. The BAL lymphocytosis of $\geq 30 \%$ was present in $50(48.5 \%)$.

The histopathological finding of TBLB and/or EBLB, suggestive of HP was seen in 52 (50\%). The common lung biopsy finding, suggestive of HP was bronchocentric inflammation in $44(43 \%)$ followed by ill-defined granuloma and lymphocytic infiltrate in 30 $(29 \%)$ cases each. The various combinations of lung biopsy finding suggestive of HP are shown in Table 4. The characteristic triad of HP i.e. all the three histopathological findings were present in $11(10.5 \%)$ only (Figures 4 and 5).

In 40 patients $(39 \%)$ the inciting antigen could not be identified by detail exposure history. The diagnosis of HP was done by respiratory symptoms, histopathological findings, BAL lymphocytosis, and radiologic findings characteristic in 27 out of 40 cases, while the diagnosis in the remaining 13 patients were on the basis of symptoms, radiological finding and by ruling out other causes of ILD.

\section{Discussion}

In the present study, $>60 \%$ patients have history of exposure to inciting antigen, with the pigeon exposure being the most common in $56 \%$ cases without any particular pigeon related occupational. HP is considered an occupational disease with exposure to various antigens at working environment. It can also occur at home without related to any particular occupation. Saltoun et al. reported a case of HP from exposure to goose dropping antigens in the community that enters buildings through their ventilation systems [22]. Birds (pigeons and parrots) are found everywhere in a local home environment, their feathers and droppings often found at roof, veranda and windows, etc. These inciting agents present at home can also leads to HP without being related to particular occupation. High levels of bird antigen can be detected in the house for prolonged periods even after the removal of birds and environmental cleanup [36]. Indian ILD registry reported HP is the most common
ILD by exposure to air cooler, without any particular occupation [16]. Recently another study revealed that increased amount of dust particles in ambient air may be one of the factor for high incidence of HP in India [37]. Although traditionally HP has been con-

Table 1. Patients demographic at presentation.

\begin{tabular}{lc}
\hline Patients characteristics & Patients $(\mathbf{n}, \mathbf{\%})$ \\
Total no of patients & 103 \\
Male & $34(33)$ \\
\hline Female & $69(67)$ \\
Mean age \pm SD & $47 \pm 12.8$ \\
\hline Median duration of symptom & 14 months \\
Symptoms <6 months & $14(13.5)$ \\
\hline Symptoms $>6$ months & $89(86.5)$ \\
\hline Exposure & \\
\hline Pigeon droopings and feathers & $58(56)$ \\
Dog dander & $02(2)$ \\
\hline Molds & $02(2)$ \\
Cotton dust & $01(1)$ \\
\hline Symptoms & \\
\hline Cough & $100(97)$ \\
Dyspnea & $94(91.2)$ \\
\hline Fever & $18(17.4)$ \\
\hline Sign & \\
Crakles & $70(68)$ \\
Digital clubbing & $16(15.5)$ \\
\hline 6 Min & \\
\hline Desaturation $>4 \%$ & $52(57)$ \\
Mean distance covered & 289 meter \\
\hline
\end{tabular}

Table 2. Detail of PFT at presentation. Parameters Patients $(n, \%)$

PFT done

101

Not able to perform

Spirometry

Restriction

$69(68.3)$

Obstruction

$4(4)$

Mixed

$5(5)$

\section{Restriction grading}

Mild

Moderate

Severe

$19(28)$

\section{DLCO}

Abnormal spirometry with normal DLCO

Abnormal spirometry with decrease DLCO

Normal spirometry with decrease DLCO

Normal spirometry with normal DLCO 
sider as an occupational disease. However we should suspect HP even without any occupational history as significant exposure history can be detected at home environment. It is better to term it as exposure related environmental disease rather than occupational disease. The inciting agent was not able find in $40 \%$ cases. It may be due to the specific IgG against various antigens and antigen challenge testing was not done, as the present study was retrospective analysis. In few earlier studies also the inciting agent was not able to identify in $>50 \%$ cases $[31,32,38]$.

Traditionally HP is classified in to 3 types i.e. acute, subacute, and chronic categories [39]. The mentioned classification is outdated as it is $>3$ decades old and of little prognostic value [40,41]. A new classification has been proposed on clinical, radiological and pathological basis into two types i.e. acute/inflammatory HP andchronic/fibrotic HP [3]. Cryptogenic HP is term a used for well-defined HP without any identifiable HP inducer [40]. In our study, chronic HP was the most common form on presentation with $89(86.4 \%)$ and remaining $14(13.5 \%)$ of acute HP. Mayo clinic also reported a similar finding, with chronic HP accounting for $78 \%$ [42]. The common chronic type of HP at presentation may be due to less severity of symptoms and slowly progressive nature of the diseases. It is also due to constant exposure to small amount of antigen from pigeons' droppings and feathers.
Table 3. The various combination of HRCT pattern suggestive of HP in 103 patients.

\begin{tabular}{lc} 
HRCT pattern $(\mathrm{n}=103)$ & Patients (n, \%) \\
Ground glass opacity and centrilobular nodules & $35(33.9)$ \\
Ground glass opacity and septal thickening & $18(17.5)$ \\
\hline Centrilobular nodules and septal thickening & $12(11.6)$ \\
Centrilobular nodules and mosaic attenuation & $08(7.7)$ \\
\hline Ground glass opacity and septal thickening & $04(3.8)$ \\
Mosaic attenuation and septal thickening & $03(3)$
\end{tabular}

Table 4. The various bronchoscopic finding of $103 \mathrm{HP}$ patients.

\begin{tabular}{lc}
\hline Bronchoscopic finding $(\mathrm{n}=103)$ & Patients $(\mathrm{n}, \mathrm{\%})$ \\
BAL lymphocytosis $>30 \%$ & $50(48.5)$ \\
$\begin{array}{lc}\text { Histopathology suggestive of HP (52 patients) } \\
\text { Bronchocentric inflammation with ill defined granuloma }\end{array}$ & $22(21.3)$ \\
Bronchocentric inflammation with lymphocytic inflammation & $22(21.3)$ \\
\hline Ill defined granuloma with lymphocytic inflammation & $8(7.7)$
\end{tabular}

Table 5.Various diagnosis studies of hypersenstivity pneumonia.

\begin{tabular}{|c|c|c|c|c|c|c|c|c|}
\hline Author & Year & No of & Inciting & Chronic/ & PFT & HRCT & Bronchoscopy/ & $\mathrm{BAL}$ \\
\hline & & patients & antigen & acute $(\%)$ & & chest & biopsy diagnosis & lymphocytosis \\
\hline Churg et al. & 2006 & 13 (7\% female) & $78 \%$ & All chronic & & $\begin{array}{l}8(62 \%) \text { ground-glass } \\
\text { opacities }(50 \%)\end{array}$ & $-/ 13(100 \%)$ & - \\
\hline Hanak et al. & 2007 & 85 (62\% female) & $75 \%$ & $78 / 22$ & $\begin{array}{c}83(97 \%) \text { restrictive } \\
\text { defect }(53 \%)\end{array}$ & $\begin{array}{c}83(98 \%) \text { ground-glass } \\
\text { opacities }(65 \%)\end{array}$ & $48(56 \%) / 25(29 \%)$ & $22(26 \%) / 13(15 \%)$ \\
\hline Morell et al. & 2008 & 86 (65\% female) & $100 \%$ & $17 / 83$ & $\begin{array}{c}78 \text { (91\%) restrictive } \\
\text { defect }(70 \%)\end{array}$ & $\begin{array}{l}41 \text { (48\%) ground-glass } \\
\text { opacities (68\%) }\end{array}$ & $-/ 33(38 \%)$ & $36(42 \%) / 30(35 \%)$ \\
\hline Adams et al. & 2018 & 155 (51\% male) & $89 \%$ & - & - & $\begin{array}{c}99(64 \%) \text { ground-glass } \\
\text { opacities (57\%) }\end{array}$ & $77(50 \%) / 29(37 \%)$ & $53(34 \%) / 26(17 \%)$ \\
\hline Present study & 2020 & 103 (67\% female) & $61 \%$ & $86 / 14$ & $\begin{array}{l}101(98 \%) \text { restrictive } \\
\text { defect }(68 \%)\end{array}$ & $\begin{array}{c}103(100 \%) \text { ground-glass } \\
\text { opacities }(55 \%)\end{array}$ & $103(100 \%) / 52(50 \%)$ & $103(100 \%) / 61(60 \%)$ \\
\hline
\end{tabular}

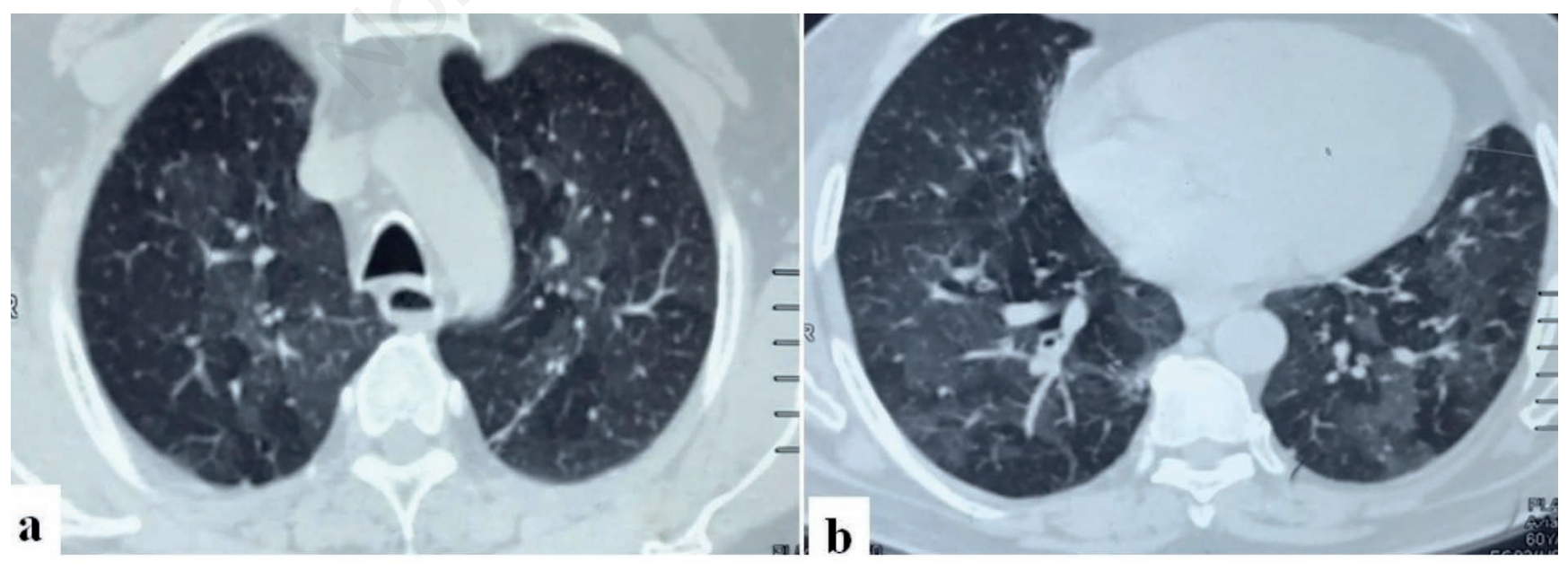

Figure 1. A 54 years old male, tea seller, presented with breathlessness and cough last 1 year. He has history of exposure to pigeons' droopings and feathers at his shop for last 1.5 year without any exposure related occupation. HRCT showing multiple centrilobular nodules with mosaic attenuation in bilateral lung (a \& b). TBLB showed bronchocentric interstitial inflammation with lymphocytic infiltrate. 
HRCT chest is an essential investigation for evaluation and classification of ILD including HP, with subtyping of disease. It frequently reveals characteristic findings of ILD where the chest $\mathrm{X}$-ray seems to be normal [43]. The main characteristic of HP on HRCT chest are centrilobular nodules and groundglass opacities $[3,42]$. Bronchiolar involvement leading to mosaic pattern is also commonly seen $[44,45]$. The changes of chronic HP are traction bronchiectasis, septal thickening and honey combing. As compared to IPF, in chronic HP the findings have no any specific zonal distribution. Majority of our patients were in chronic form of disease but still $>60 \%$ cases showed centrilobular nodules and ground glass opacities. It means that there is still a chance of reversing of the disease and better prognosis. The chronic non reversible find- ings were limited to $<6 \%$ in our study, even septal thickening was present in nearly $30 \%$ of patients. The HRCT changes not only help in diagnosis and subtyping of disease, but also to guided patient treatment, prognosis and respond.

Bronchoscopy plays an important role in diagnosis of HP. BAL fluid collection/analysis and lung biopsy are the major procedures done through bronchoscopy. BAL fluid lymphocytic pattern raises the probability of HP, as $>80 \%$ of chronic HP have $>20 \%$ lymphocytes [46]. But the lymphocyte count may be normal or even less than normal in some chronic HP $[3,46,47]$. So BAL lymphocytosis is not a definite criteria for diagnosis, however BAL lymphocytosis $(>30 \%$ non-smoker and $>20 \%$ smokers) with HRCT changes is considered as one of the standard cri-
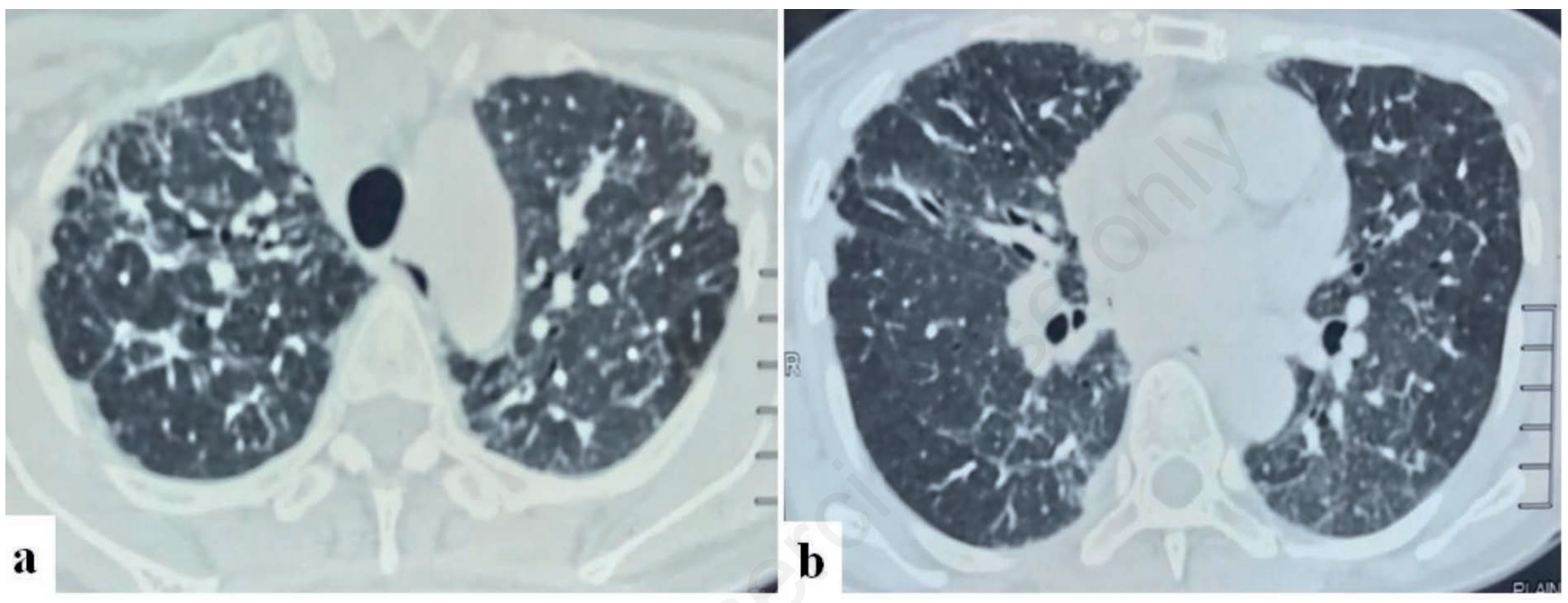

Figure 2. A 57-year-old female, housewife, presented with breathlessness and cough for the last 1.5 years, with history of exposure to pigeons' droopings and feathers at her house without any exposure- related occupation for last 25 years. The chest HRCT showed multiple centrilobular nodules and septal thickening with few fibrosis in bilateral lung $(a, b)$. TBLB showed bronchocentric interstitial inflammation and alveolar septal thickening with lymphocytic infiltrates.
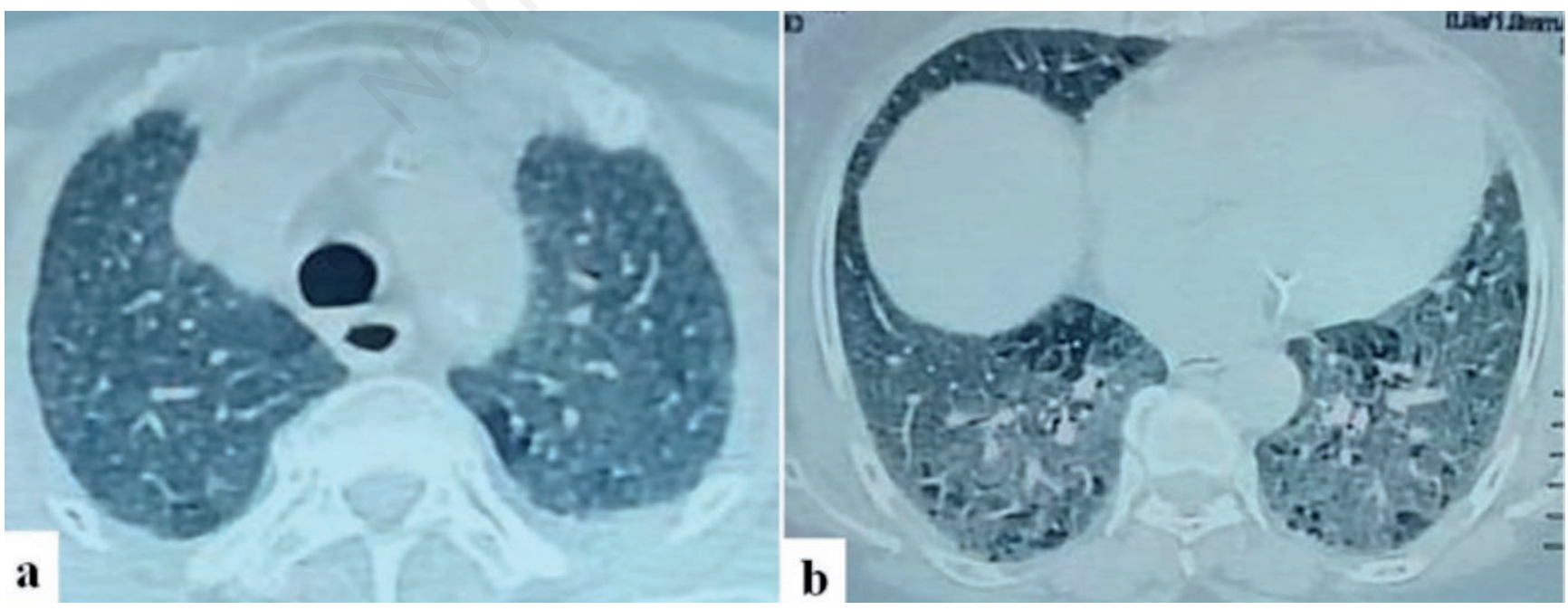

Figure 3. A 63-year-old female, housewife, presented with of breathlessness and cough for the last 4 years, with history of exposure to pigeons' droopings and feathers at her house for same duration. The chest HRCT showed multiple centrilobular nodules and ground glass opacities with few cystic lesions in bilateral lung $(a, b)$. The TBLB showed fibrous thickening of alveolar septa, lymphocytic inflammatory cells and peribronchial fibrosis and BAL lymphocyte was $82 \%$. 
teria of HP diagnosis $[3,43,48]$. The BAL fluid of low lymphocyte CD4:CD8 ratio is suggestive for $\mathrm{HP}$, but this is also nonspecific $[3,39]$. As it is affected by type of inhaled antigen, the intensity of exposure, smoking and the disease stage $[5,49,50]$. In the present study BAL lymphocytosis $>30 \%$ was present in $48.5 \%$. Similarly, Adams TN et al found that the BAL lymphocytosis of $>30 \%$ was present in $42 \%$ [51]. Other earlier studies showed high BAL lymphocytosis with range from 64 to $83 \%$ $[46,52]$. The higher rate of lymphocytosis in these studies were due to the cut off $>20 \%$ lymphocyte. If we take the cutoff value of $>20 \%$, it was present in $61(60 \%)$, which is a quit similar to above studies.

The histopathologic features of HP are distinctive but not pathognomonic. The characteristic histopathological triad of inflammatory HP are lymphoplasmocytic infiltrates, airway-centric lymphocytic infiltratesand poorly formed granulomas [3,32]. While in chronic HP the finding are nonspecific with fibrosis predominant. The fibrosis is unclassifiable and more airway-centered. Advanced fibrosis with normal airways, within and/or around the small airways and associated inflammatory HP will help to confirm diagnosis of chronic HP $[3,33,53]$. In our study the histopathological diagnosis on TBLB was found in $50 \%$. Different studies have showed different diagnostic yield of histopathogical diagnosis in HP range from 9\%-75\% [3,42,46,5153]. Recent meta-analysis of TBLB revealed a diagnostic yield of $64.3 \%$ [54]. Morell et al. found that the characteristic triad of HP
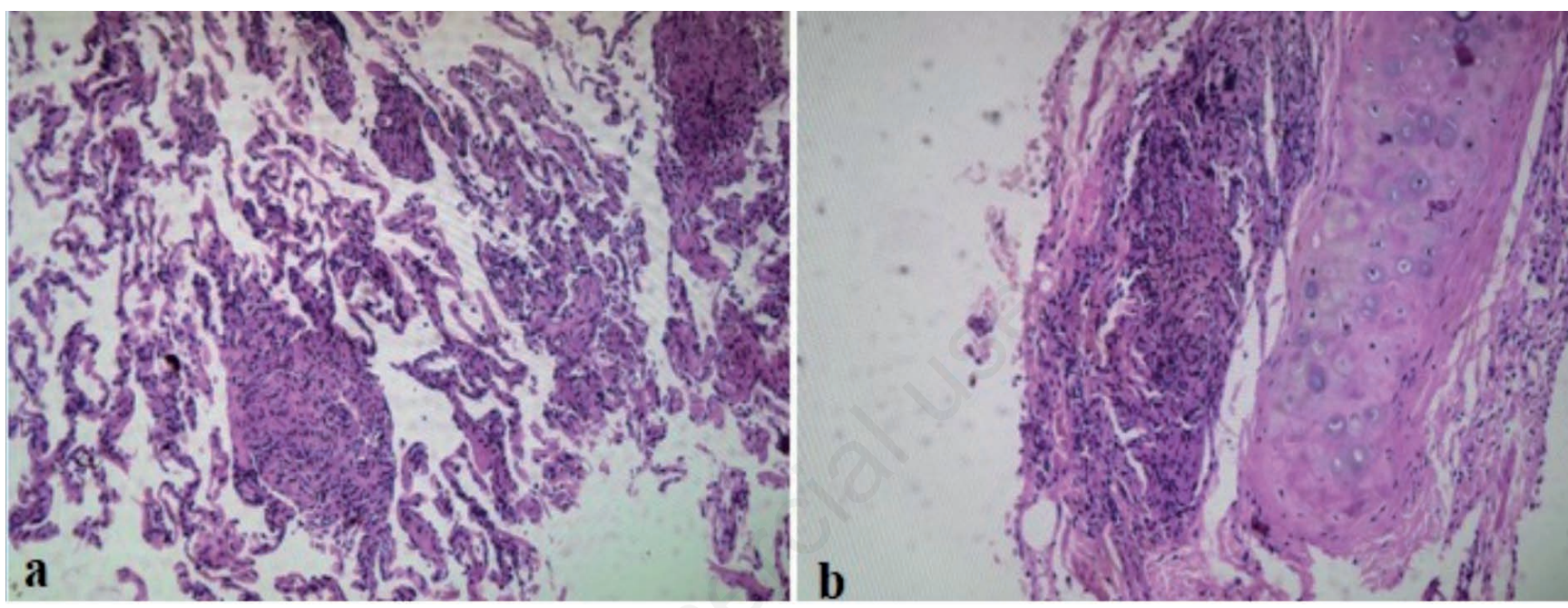

Figure 4. A 52-year-old female, housewife, presented with breathlessness and cough for the last 3 months, with history of exposure to pigeons' drooping and feather at her house for last 5 years. The chest HRCT chest showed multiple centrilobular nodules and ground glass opacities with minimal mosaic attenuation in bilateral lung. The TBLB showed interstitial granuloma on low power view (a) and granuloma near bronchial wall on high power view (b).
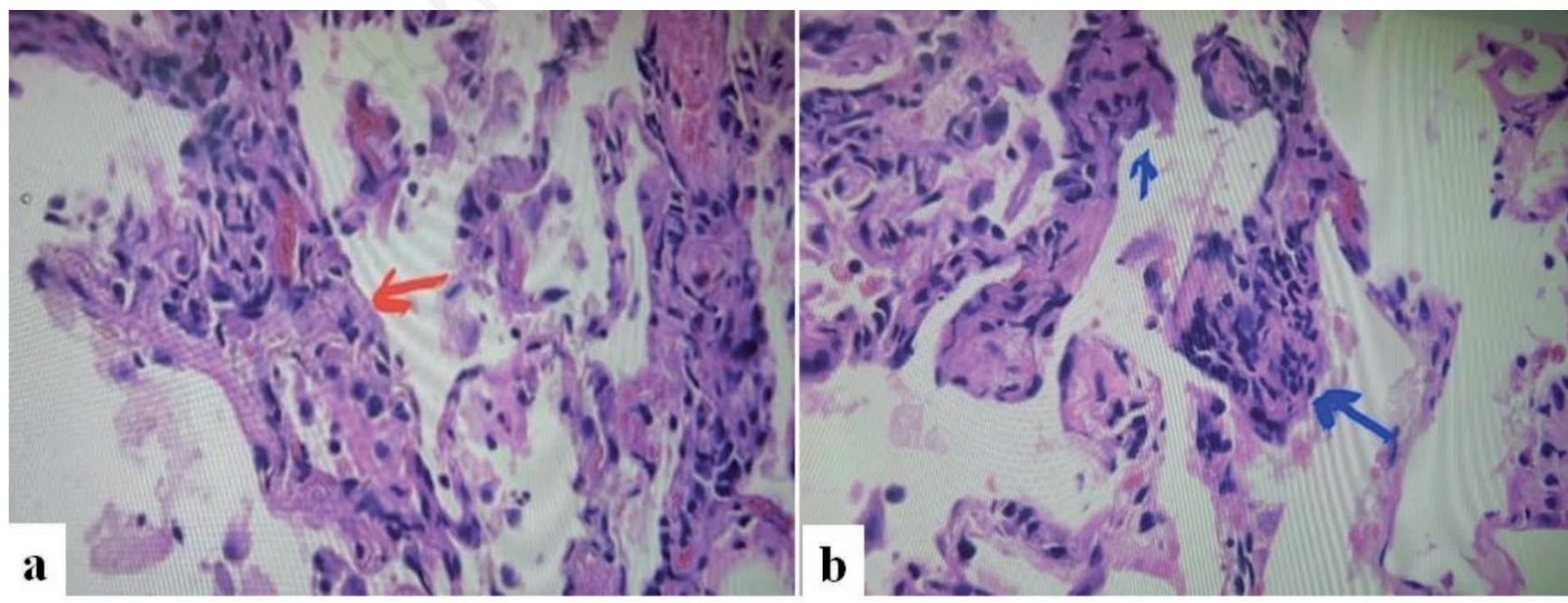

Figure 5. A 47-year-old female, housewife, presented with of cough and breathlessness for 7 years, with history of exposure to pigeons' drooping and feather at her home without any pigeon-related occupation for same duration. She also had history of acute respiratory illness after acute exposure to pigeons 14 years back. The chest HRCT showed multiple centrilobular nodules and ground glass opacities in bilateral lung. The TBLB showed interstitial thickening with lymphocytic cell (red arrow in a) and ill-defined granuloma (blue arrow in b). 
on TBLB was found in only $9 \%$, but at least 1 of these findings was seen in nearly $70 \%$ [46]. Our result is quite similar with nearly $48 \%$ showed at least 2 findings, while all the 3 finding was seen in $11 \%$. Adams $\mathrm{TN}$ et al shown that the combination of TBLB with BAL increase the diagnostic yield and decrease the need of surgical biopsy [51]. Sheth et al. found that TBLB in combination with clinical and HRCT finding may provide accurate diagnosis in $20-30 \%$ of fibrotic ILD [55]. So bronchoscopic procedures (BAL and TBLB) are still have good diagnostic yield in HP when combine with clinical and HRCT finding and also decrease the need of invasive surgical biopsy. The thoracic surgeons are rarely available for routine diagnostic lung biopsy in our country and an invasive procedure with cost and hospital stay. We advised to do bronchoscopic procedure in all HP suspected to confirm the diagnosis with less invasive, day care procedure with minimal cost and complications. The various previous studies of HP diagnosis along with present study are summarized in Table 5. There are multiple proposed diagnostic criteria for HP diagnosis. The diagnosis should be done either with one of the criteria or at least with positive exposure with HRCT changes and histopathological finding [37,56-58].

Recently many biomarkers in BAL fluid and blood are investigating for the potential of HP diagnosis and its prognosis prediction. The various biomarker in research phase for HP are Krebs von den Lungen-6 (KL-6), natural killer (NK), natural killer T-like cells (NKT-like cells), chitotriosidase, surfactant protein D, cathepsin-K and chemokines (CCL17, CCL18, vascular endothelial growthfactor, IL-8, epithelial neutrophil-activating peptide 78 [ENA-78]) [3,59-62]. The KL-6, NK and NKT like cell are commonly studied biomarkers. Lanzarone et al. in a study of chronic HP found that KL-6 level had increased in $80 \%$ patients. BAL LK6 is higher in patients with GGO and CLN on HRCT. They also found that BAL lymphocytosis have direct correlation with KL-6 concentration [59]. Another study with 100 ILD patients from Italy found that the BAL KL-6 and NKT like cell level were higher in chronic HP patients [60]. d'Alessandro et al. in a study of 96 ILD patients also found that the KL-6 concentration was significantly higher in chronic HP and IPF patients compared to healthy controls with $\mathrm{P}<0.006$ [61]. These biomarker analyses are easy and minimally invasive than biopsy, for diagnosis of HP. In near future the biomarkers might replace the need of biopsy for diagnosis in near future with prognostic value.

Regarding limitation, there are few limitations of present study. It is a retrospective study so detail of the antigen exposure is difficult to ascertain. The other limitation is, it is a single centre study from north India as India has different geography and environment with different environmental exposure at different places. Other limitation is that identification of inciting antigen is not confirmed by serology.

\section{Conclusions}

HP is considered as an occupational disease. It is better to term it as exposure related environmental disease, as it can occur without any occupational exposure. Multidisciplinary discussion is best way to diagnosis with involvement of minimum a pulmonologist, radiologist and pathologist. Bronchoscopy with BAL and lung biopsy should do in all suspected cases to confirm diagnosis in our country as it is less invasive day care procedure with less complications and cost compared to surgical and cyro-transbronchial lung biopsy.

\section{References}

1. Ramazzini B. De morbis artificium diatriba. Modena: Antonio Capponi; 1700. pp. 360.

2. Pepys J, Riddell RW, Citron KM, Clayton YM. Precipitins against extracts of hay and moulds in the serum of patients with farmer's lung, aspergillosis, asthma, and sarcoidosis. Thorax 1962;17:366-74.

3. Vasakova M, Morell F, Walsh S, et al. Hypersensitivity pneumonitis: Perspectives in diagnosis and management. Am J Respir Crit Care Med 2017;196:680-689.

4. Chandra D, Cherian SV. Hypersensitivity pneumonitis. Treasure Island: StatPearls [Internet].

5. Selman M, Pardo A, King TE. Hypersensitivity pneumonitis insights in diagnosis and pathobiology concise clinical review. Am J Respir Crit Care Med 2012;186:314-24.

6. Coultas DB, Zumwalt RE, Black WC, Sobonya RE. The epidemiology of interstitial lung diseases. Am J Respir Crit Care Med 1994;150:967-72.

7. Bang KM, Weissman DN, Pinheiro GA, et al. Twenty-three years of hypersensitivity pneumonitis mortality surveillance in the United States. Am J Ind Med 2006;49:997-1004.

8. Solaymani-Dodaran M, West J, Smith C, Hubbard R. Extrinsic allergic alveolitis: incidence and mortality in the general population. QJM 2007;100:233-7.

9. Hyldgaard C, Hilberg O, Muller A, Bendstrup E. A cohort study of interstitial lung diseases in central Denmark. Respir Med 2014;108:793-9.

10. Thomeer MJ, Costabel U, Rizzato G, et al. Comparison of registries of interstitial lung diseases in three European countries. Eur Respir J 2001;32:s114-8.

11. Depierre A, Dalphin JC, Pernet D, et al. Epidemiological study of farmer's lung in five districts of the French Doubs province. Thorax 1988;43:429-35.

12. Rodriguez de Castro F, Carrillo T, Castillo R, et al. Relationships between characteristics of exposure to pigeon antigens. Clinical manifestations and humoral immune response. Chest 1993;103:1059-63.

13. Sen T, Udwadia ZF. Retrospective study of interstitial lung disease in a tertiary care centre in India. Indian J Chest Dis Allied Sci 2010;52:207-11.

14. Kumar R, Gupta N, Goel N. Spectrum of interstitial lung disease at a tertiary care centre in India. Pneumonol Alergol Pol 2014;82:218-26.

15. Dhooria S, Agarwal R, Sehgal IS, et al. Spectrum of interstitial lung diseases at a tertiary center in a developing country: A study of 803 subjects. PLoS One 2018;13:e0191938.

16. Singh S, Collins BF, Sharma BB, et al. Interstitial lung disease in India. Results of a Prospective Registry. Am J Respir Crit Care Med 2017;195:801-13.

17. Fink JN, Ortega HG, Reynolds HY, et al. Needs and opportunities for research in hypersensitivity pneumonitis. Am J Respir Crit Care Med 2005;171:792-8.

18. Fernández Pérez ER, Koelsch TL, Leone PM, et al. clinical decision-making in hypersensitivity pneumonitis: diagnosis and management. Semin Respir Crit Care Med 2020;41: 214-28.

19. Aburto M, Herráez I, Iturbe D, Jiménez-Romero A. Diagnosis of idiopathic pulmonary fibrosis: differential diagnosis. Med Sci (Basel) 2018;6:73.

20. Rodrigo MJ, Benavent MI, Cruz MJ, et al. Detection of specific antibodies to pigeon serum and bloom antigens by enzyme 
linked immunosorbent assay in pigeon breeder's disease. Occup Environ Med 2000;57:159-64.

21. Johannson KA, Elicker BM, Vittinghoff E, et al. A diagnostic model for chronic hypersensitivity pneumonitis. Thorax 2016; 71:951-4.

22. Saltoun CA, Harris KE, Mathisen TL, Patterson R. Hypersensitivity pneumonitis resulting from community exposure to Canada goose droppings: when an external environmental antigen becomes an indoor environmental antigen. Ann Allergy Asthma Immunol 2000;84:84-6.

23. Jacobs RL, Andrews CP, Coalson JJ. Hypersensitivity pneumonitis: beyond classic occupational disease-changing concepts of diagnosis and management. Ann Allergy Asthma Immunol 2005;95:115-28.

24. Sema M, Miyazaki Y. Environmental levels of avian antigen are relevant to the progression of chronic hypersensitivity pneumonitis during antigen avoidance. Immun Inflamm Dis 2018;6:154-62.

25. Salisbury ML, Myers JL, Belloli E A, et al. Diagnosis and treatment of fibrotic hypersensitivity pneumonia. Where we stand and where we need to go. Am J Respir Crit Care Med 2017; 196:6909.

26. Johannson KA, Elicker BM, Vittinghoff E, et al. A diagnostic model for chronic hypersensitivity pneumonitis. Thorax 2016;71:951-954.

27. Lynch DA, Rose CS, Way D, King TE Jr. Hypersensitivity pneumonitis: sensitivity of high-resolution CT in a populationbased study. AJR Am J Roentgenol 1992;159:469-472.

28. Lynch DA, Newell JD, Logan PM, et al. Can CT distinguish hypersensitivity pneumonitis from idiopathic pulmonary fibrosis? Am J Roentgenol 1995;165:807-11.

29. Silva CI, Müller NL, Lynch DA, et al. Chronic hypersensitivity pneumonitis: differentiation from idiopathic pulmonary fibrosis and nonspecific interstitial pneumonia by using thin-section CT. Radiology 2008;246:288-97.

30. Reyes CN, Wenzel FJ, Lawton BR, Emanuel DA. The pulmonary pathology of farmer's lung disease. Chest 1982; 81:142-6.

31. Coleman A, Colby TV. Histologic diagnosis of extrinsic allergic alveolitis. Am J Surg Pathol 1988;12:514-8.

32. Takemura T, Akashi T, Ohtani Y, et al. Pathology of hypersensitivity pneumonitis. Curr Opin Pulm Med 2008;14: 440-54.

33. Churg A, Muller NL, Flint J, Wright JL. Chronic hypersensitivity pneumonitis. Am J Surg Pathol 2006;30:201-8.

34. Pellegrino R, Brusasco GVV, Crapo RO, et al. Interpretative strategies for lung function tests. Eur Respir J 2005;26:948-68.

35. Aggarwal AN, Agarwal R, Dhooria S, et al. Joint Indian Chest Society $\square$ National College of Chest Physicians (India) guidelines for spirometry. Lung India 2019;36:s1-35.

36. Craig TJ, Hershey J, Engler RJ, et al. Bird antigen persistence in the home environment after removal of the bird. Ann Allergy 1992;69:510-2.

37. Singh S, Collins BF, Bairwa M, et al. Hypersensitivity pneumonitis and its correlation with ambient air pollution in urban India. Eur Respir J 2019;53:1801563.

38. Mooney JJ, Elicker BM, Urbania TH, et al. Radiographic fibrosis score predicts survival in hypersensitivity pneumonitis. Chest 2013;144:586-92.

39. Patel AM, Ryu JH, Reed CE. Hypersensitivity pneumonitis: current concepts and future questions. J Allergy Clin Immunol 2001;108:661-70.

40. Fernández Pérez ER, Swigris JJ, Forssén AV, et al. Identifying an inciting antigen is associated with improved survival in patients with chronic hypersensitivity pneumonitis. Chest 2013;144:1644-51.

41. Richerson HB, Bernstein IL, Fink JN, et al. Guidelines for the clinical evaluation of hypersensitivity pneumonitis: report of the Subcommittee on Hypersensitivity Pneumonitis. J Allergy Clin Immunol 1989;84:839-44.

42. Hanak V, Golbin JM, Ryu JH. Causes and presenting features in 85 consecutive patients with hypersensitivity pneumonitis. Mayo Clin Proc 2007;82:812-6.

43. Lacasse Y, Selman M, Costabel U, et al. Clinical diagnosis of hypersensitivity pneumonitis. Am J Respir Crit Care Med 2003;168:952-8.

44. Ryu JH, Myers JL, Swensen SJ. Bronchiolar disorders. Am J Respir Crit Care Med 2003;168:1277-92.

45. Bhattacharyya P, Dasgupta S, Paul M, et al. High-resolution computerized tomography changes in diffuse parenchymal lung disease from chronic hypersensitivity pneumonitis related to bird antigen. Lung India 2018;35:215-9.

46. Morell F, Roger A, Reyes L, et al. Bird fancier's lung: a series of 86 patients. Medicine (Baltimore) 2008;87:110-30.

47. Caillaud DM, Vergnon JM, Madroszyk A, et al. Bronchoalveolar lavage in hypersensitivity pneumonitis: a series of 139 patients. Inflamm Allergy Drug Targets 2012;11:15-9.

48. The BAL Cooperative Group Steering Committee. Bronchoalveolar lavage constituents in healthy individuals, idiopathic pulmonary fibrosis, and selected comparison groups. Am Rev Respir Dis 1990;141:169-202.

49. Barrera L, Mendoza F, Zuñiga J, et al. Functional diversity of T-cell subpopulations in subacute and chronic hypersensitivity pneumonitis. Am J Respir Crit Care Med 2008;177:44-55.

50. Meyer KC, Raghu G, Baughman RP, et al. An official American Thoracic Society clinical practice guideline: the clinical utility of bronchoalveolar lavage cellular analysis in interstitial lung disease. Am J Respir Crit Care Med 2012;185:1004-14.

51. Adams TN, Newton CA, Batra K, et al. Utility of bronchoalveolar lavage and transbronchial biopsy in patients with hypersensitivity pneumonitis. Lung 2018;196:617-22.

52. Cormier Y, Btlanger J, Leblanc $\mathrm{P}$, Laviolette $\mathrm{M}$. Bronchoalveolar lavage in farmers' lung disease: diagnostic and physiological significance. Br J Industrial Med 1986; 43:401-5.

53. Wang P, Jones KD, Urisman A, et al. Pathological findings and prognosis in a large prospective cohort of chronic hypersensitivity pneumonitis. Chest 2017;152:502-9.

54. Sharp C, McCabe M, Adamali H, Medford AR. Use of transbronchialcryobiopsy in the diagnosis of interstitial lung disease-a systematic review and cost analysis. QJM 2017; 110:207-14.

55. Sheth JS, Belperio JA, Fishbein MC, et al. Utility of transbronchialvs surgical lung biopsy in the diagnosis of suspected fibrotic interstitial lung disease. Chest 2017;151:389-99.

56. Terho EO. Diagnostic criteria for farmer's lung disease. Am J Ind Med 1986;10:329.

57. Cormier Y, Lacasse Y. Keys to the diagnosis of hypersensitivity pneumonitis: the role of serum precipitins, lung biopsy, and high-resolution computed tomography. Clin Pulm Med 1996;3:72-7.

58. Schuyler M, Cormier Y. The diagnosis of hypersensitivity pneumonitis. Chest 1997;111:534-36.

59. Lanzarone N, Gentili F, Alonzi V, et al. Bronchoalveolar lavage and serum KL $\square 6$ concentrations in chronic hypersensitivity 
pneumonitis: correlations with radiological and immunological features. Intern Emerg Med 2 020. doi: 10.1007/s11739-02002281-8.

60. d'Alessandro M, Carleo A, Cameli P, et al. BAL biomarkers' panel for differential diagnosis of interstitial lung diseases. Clin Exp Med 2020;20:207-16.
61. d'Alessandro M, Bergantini L, Cameli P, et al. Serum KL-6 levels in pulmonary Langerhans' cell histiocytosis. Eur J Clin Inves 2020;50:e13242.

62. Bergantini L, Cameli P, d'Alessandro M, et al. NK and NKTlike cells in granulomatous and fibrotic lung diseases. Clin Exp Med 2019;19:487-94. 